\section{Iatrogenesis and Medical Error}

\section{Dear Editors:}

I feel that some commentary, although perhaps belated, is necessary concerning the article, latrogenesis and Medical Error: The Case for Medical Malpractice Litigation by Barry R. Furrow, which appeared in the October 1981 issue. When two agendas may be operative, it is imperative that the author acknowledge this possibility. If a psychiatrist were to write an article explaining the benefirs of charging high fees in psychotherapy and elaborating on how this serves as an impetus to the patient to be more engaged in the psychotherapy, avoid resistance, make progress sooner, etc., he should at least acknowledge that another agenda is also present - that the fee charged will impact on the psychiatrist's income.

Analogously, a discussion by an attorney of the benefits of malpractice litigation under the present tort law system should acknowledge the presence of a second agenda. There is an economic interest on the part of lawyers that the present system be maintained. If this acknowledgement is made, it is then fair to say that there may also be an impact upon patient care delivery. Otherwise, one does not know whether the attorney is concerned with medical outcome, or using an argument about medical outcome for his own economic interests.

Perhaps Attorney Furrow has never participated in, nor ever plans to participate in, any malpractice litigation. If so, he should so state, since this would add credibility to the article. However, it seems likely that in this well written article first hand expertise in addition to literary skill is present.

I would suggest that evidence can be found in Mr. Furrow's article that suggests an attorney's point of view and a very different one than the pa. tient would hold. He states: "Almost 80 percent of the incidents that lead to malpractice claims occur in hospitals, reflecting the primacy of the hospital as the locus of most medical practice." This is certainly a parochial, and perhaps self-serving, way of defining "the locus of most medical practice."
It may be true that hospitals are this locus. However, operationally this might be demonstrated by stating, for example, that this is the perception of most patients, that this is where the bulk of health care dollars are spent, or that this is where the majority of physicians' time is spent (if any of these possibilities are true) rather than by defining where medicine is practiced by where malpractice suits originate. Lawyers may define it this way, but patients do not. The other agenda is becoming evident.

The editor, too, should be aware that when an article is accepted for publication and appears in print in a scientific journal, an aura of expertise is vested upon the author. The thesis of $\mathrm{Mr}$. Furrow's article is not that the maintenance of the tort law system is important from the standpoint of preserving a patient's rights (a field in which the author is expert), but rather that it is important from the stand. point of improving the level of medical care (a field in which he is not). He could state that he is drawing conclusions from the literature review he has done, but the acknowledgement of his basic conflicting agendas would be a concession that he may not be a dispassionate and unbiased investigator. Identifying himself as an attorney does not acknowledge the conflict, as it is overridden by the aura of expertise.

I am certainly in agreement with the author's concluding statement that "any 'no fault' system or national health insurance plan, if it seeks to reduce medical malpractice and ensuing litigation, must also provide an alternative means of deterring iatrogenic outcomes." But in the article, the statement appears gratuitous, since what Mr. Furrow really means is that the tort law system should be maintained.

I must hasten to add (emphasis on the "must") that I, as a physician writing this letter, have some interest in malpractice law that is for the benefit of physicians and not connected to reducing medical error (although hopefully the latter is the primary interest

\section{Continued on page 38}

AMERICAN SOCIETY OF LAW \& MEDICINE, INC.

\author{
Executive Committee \\ Sidney Scherlis, M.D. \\ President \\ Thomas E. Cargill, Jr., J.D. \\ President-Elect \\ Aubrey Milunsky, M.D. \\ Vice President \\ Lee J. Dunn, Jr., J.D., LL.M. \\ Secretary \\ Angela R. Holder, J.D., LL.M \\ Treasurer \\ Elliot L. Sagall, M.D. \\ Immediate Past President \\ lohn A. Norris, J.D., M.B.A. \\ Chairmar, Bd of Director \\ Douglas Danner, J.D. \\ General Counsel \\ A. Edward Doudera, J.D \\ Executive Director \\ Board of Directors \\ Medicine \\ Donald B. Barkan, M.D., F.A.C.P \\ Ronald E. Cranford, M.D. \\ Gary R. Epler, M.D. \\ Rachard F. Gibbs, M.D., J.D. \\ Kevin M. McIntyre, M.D., J.D. \\ Robert R. Mezer, M.D. \\ Robert R. Mezer, M.D.
Arnold S. Relman, M.D. \\ Alain B. Rossier, M.D. \\ Alain B. Rossier, M.D.
Margery W. Shaw, M.D., J.D \\ Gerald $F$ Winkler, MD. \\ Lau \\ W.Thomas Berriman, J.D \\ Neil L. Chayet, J.D. \\ Marvin S. Fish, J.D. \\ Richard W. Galiher, Jr., J.D. \\ Richard W. Galiher, \\ J. Douglas Peters, J.D. \\ Leslie Steven Rothenberg. J.D. \\ Robert C. Strodel, J.D. \\ Rosert C. Stromberg, J.D. \\ Ross E. Stromberg, J.D.
Stephen M. Weiner, J.D. \\ Nursing \\ Mary M. Clishing, B.S.N., J.D \\ jane L. Greenlaw, R.N., M.S. J.D \\ Cynthia E. Northrop, R.N., M.S., J.D \\ Dentistry \\ Paul Goldhaber, D.D.S \\ Education \\ George J. Annas, J.D., M.P.H \\ William J. Curran, LL.M., S.M.Hyg \\ Richard G. Huber, J.D. \\ Arthur F. Southwick, J.D., M.B.A. \\ Other Health Care Providers \\ Patrick R. Cartoll, J.D. \\ Thomas Durane M. D. \\ Sandra G. Nye, M.S.W., J.D \\ Mandra I. Nye, M.S. W. T. D. \\ David G. Warren J.D. \\ Iudiriary \\ Honorable Kathleen Ryan Dacey \\ Honorable Robert L. Hermann \\ Honorable Max Rosenn \\ Honorable Irvin Stander \\ Insurance \\ James F. Holzer, J.D. \\ Michael Jusell \\ John Larkin Thompson, J.D. \\ David Z. Webster. LL.B., M.B.A \\ At-Large \\ Paul J.Connors, M.D. J.D \\ Harry W. Dahl, j.D. \\ Reid F. Holbrook, J.D. \\ Albert R. Jonsen, \\ fohn ]. Paris, S.J. \\ Harvey E. Pies, J.D. \\ Barry C. Reed. J.D. \\ Ira Michael Shepard, J.D. \\ Pail D. Rheingold, L.L.B.
}


Correspondence -

continued from page 2

of the physician). I am sure that a response from Mr. Furrow would be most interesting and thoughtful.

Donald L. Feinsilver, M.D. Assistant Professor of Psychiatry The Medical College of Wisconsin Milwaukee, Wisconsin

\section{Professor Furrow responds:}

Dr. Feinsilver sounds a major theme, and a minor one, in response to my discussion of medical malpractice litigation. His major theme is that any discussion by a lawyer of the impact of malpractice litigation on medical practice is suspect. A "second agenda" exists, he complains, in which the lawyer's economic interest leads to bias. Malpractice litigation generates fees for lawyers, and doctrinal and other legal changes which expand the liability of physicians and providers increase lawyers' income. I am a lawyer, and therefore, says Feinsilver, my biases are painfully evident. Unfortunately for Feinsilver, I am an academic law. yer; I have never engaged in malpractice litigation, and have no vested interest in income related to such litigation. Rather, I have the academic's interest in evaluating malpractice litigation as only one possible approach among many for improving medical practice, as a form of "microregulation," as my article characterizes it. Feinsilver, however, cites "evidence" to support his theme: I define "medical practice," he says, by reference to the fact that most "incidents that lead to malpractice claims occur in hospitals." This misses the point: I do not define medical practice, but instead point out the centrality of the hospital setting (as do the two studies I review) in causing jatrogenesis and of the need to study hospital practice and incentives which affect physicians and others within that setting.

The major theme has a thin timbre, being essentially an ad hominem argument that, by attacking my objectivity, seeks to undermine my conclusions. Surely a substantive response is possible. Is malpractice litigation counterproductive, producing costs in defen- sive medicine that ourweigh any incentive effects produced? Has evidence been produced by systematic study as to a positive correlation between overall improvements in medical practice, and reductions in medical error, traceable to the effect of legal rules and the threat of lawsuits? No frontal attack is made on either my facts or my conclusions. The point of the two New England Journal of Medicine studies of iatrogenesis in hospitals was that the problem is substantial, larger than commonly perceived, and little is being done. The relation of the legal system to these problems is suggested in a perjorative fashion, without the evidence of systematic study that is apparent in tracing iatrogenesis. Dr. Feinsilver falls into the same error as the authors of the studies do, for reasons relating to a misunderstanding of the contours and limits of litigation.

The minor theme sounded by Feinsilver (and it is almost inaudible) is that the tort system's role is to protect patients' rights (however defined) but not to improve the quality of medical care through the reduction of medical error. The underlying assumption is apparently that medical error, whether avoidable or not, cannot be appropriately evaluated through litigation. An argument can be made for this position,' but Feinsilver does not make it. The need for a systematic mechanism for deterring medical practices leading to iatrogenic results is a real one, and it would seem that physicians have not succeeded through selfgovernance in reducing those errors, even though, as Feinsilver concludes, such "is the primary interest of the physician."

\section{References}

1. See, e.g. Gorowitz and Maclntyre, Toward a Theory of Medical Fallibility, JOURNAL OF MEDICINE S PHILOSOPHY 1:51 (1976).

\section{The Editors reply:}

Donald L. Feinsilver's comments on latrogenesis and Medical Error: The Case for Medical Malpractice Litigation by Barry R. Furrow, J.D., include the statement: "The editor, too, should be aware that when an article is accepted for publication and appears in print in a scientific journal, an aura of expertise is vested upon the author." This statement requites our reply.

Professor Furrou's piece arises from his oun particular expertise, training, and knowledge, just as all articles reflect their authors' points of vieu. His article, again like all articles that appear in LAW', MEDI. CME HEALTH CARE, is intended not only to act as a catalyst for meaningful dialogue and discussion, but also as authority for the propositions stated. Any article that is published in LAW, MEDICINE \& HEALTH CARE is not intended to be the absolute or final word on a subject, but only as authority as described by the particular author. Each article that is published by LAX', MEDICINE \& HEALTH CARE must, by necessity, leave room for debate and differing viewpoints. Such appears to have been the case given Dr. Feinsilver's comments. Concomitantly, Dr. Feinsilver, too, must recognize that his vieus can only be authoritative in the context in which they are stated. Simply put, Dr. Feinsilver disagrees with Professor Furrow. But the inference that no aura of expertise surrounds Professor Furrou' because of this should not, nor can it be, taken at face value.

Miles J. Zaremski, J.D.

Editor-in-Chief

\section{Team Talk: Ways of Arriving at Decisions}

\section{Dear Editors:}

To the many points made in Edmund Erde's article, Notions of Teams and Team Talk in Health Care: Implications for Responsibility (published in October 1981), it is useful to add the dimension of the decision-making process.

Essentially, teams have three potential ways of arriving at decisions: byauthority, by-majority vote, and byconsensus. For clinical teams, the bymajority vote option has little appeal because in clinical situations the primary concern is carrying out the decisions, not just reaching decisions. Thus, by-majority vote has appeal for governance situations in hospitals where the focus is on "What will we decide?" The by-authority approach has considerable appeal for acute clinical situations, and the by-consensus 